\title{
Extended Technology Acceptance Model to Examine the Use of Google Forms - based Lesson Playlist in Online Distance Learning
}

\author{
Fritz M. Ferran \\ De La Salle Santiago Zobel School - Vermosa Campus, Imus City, Philippines, \\ https://orcid.org/0000-0003-2964-6019 \\ Email Correspondence: fritz.ferran@dlszobel.edu.ph
}

\begin{abstract}
Shifting to online distance learning due to the COVID-19 pandemic challenged educators' roles as instructional materials designers. This study aimed to examine the students' acceptance of the teacher-designed e-learning tool called Google Forms-based Lesson Playlist (GF-LP) in a home-based online distance learning environment. This quantitative research analyzed 570 responses from Grades 11 and 12 students at a private school in the Philippines using the partial least squares-structural equation modeling. Results showed that perceived self-efficacy and system quality strongly affect the users' perceived ease of use while perceived ease of use highly influenced the students' perceived usefulness of GF-LP. Facilitating conditions do not affect the users' attitudes towards using the e-learning tool, which confirmed the effective utilization of GF-LP in online distance learning. The relationships between the original constructs of the Technology Acceptance Model (TAM) were also presented. This study recommends the use of GF-LP or its features for remote learning.
\end{abstract}

Keywords: digital learning technology, extended technology acceptance model, COVID-19, online distance learning, Philippine Senior High School students, PLS-SEM

\subsection{Introduction}

COVID-19 pandemic challenged educators to adapt teaching online (König et al., 2020) as a response to control the spread of the coronavirus disease (Toquero, 2020). Hence, they need to explore designing online learning tools and appropriate teaching pedagogy to assist their students in online distance learning. Today, designing appropriate instructional materials comes with great ease brought by technological advancements in the digital age of the 21st century ((Fei \& Hung, 2016). Digital Learning Technology (DLT) adoption in times like this addresses the physical limitations of delivering the lessons and allows students to continue learning anytime and anywhere Mothibi, 2015). Adopting various digital learning technologies into the learning environment helps achieve the desired goals, learning process, and learning outcomes of educational activities Ozerbas \& Erdogan, 2016).

However, DLT adoption poses barriers, especially during online distance learning. According to Panda and Mishra (2007) and Ancho (2020), the teachers perceived that the significant challenges in utilizing DLT include weak internet connection, insufficient training, lack of institutional 
policy, and poor instructional design support for e-learning. The majority of the reviewed literature focused on teachers' perceptions of DLT adoption barriers. Thus, there is a need to elicit information periodically from the students to address these barriers to improve digital learning technologies continuously (Adnan \& Anwar, 2020). Similarly, Almaiah, Alamri, \& Al-rahmi (2019) emphasized that students' acceptance of mobile learning is essential to guarantee online education success. Hence, designing a specific e-learning tool that would address the DLT adoption barriers in an online learning environment is needed. Furthermore, adopting the online distance learning environment can be successful through a significant pedagogical transformation aided by an appropriate e-learning tool that is designed carefully such that it considers the students' realities at home.

In this study, the teachers of the respondents developed a Google Forms-based Lesson Playlist (GF-LP), a self-made e-learning tool that is used to address the digital technology adoption barriers in the first implementation of online distance learning in the Philippines. A sample template of GF-LP was provided to the teachers for uniformity. Thus, this study sought to examine the use of Google Formsbased Lesson Playlist as students' e-learning tool in their different subjects in a home-based online distance learning.

\section{Google Forms - Based Lesson Playlist as a Digital Learning Technology in ODL}

The abrupt transition from traditional to online instruction as an emergency response to the pandemic provides an opportunity for a wider acceptance of technology-aided education (Rajab et al., 2020). Digital Learning Technology (DLT) refers to a set of hardware and software devices that allow information and knowledge to be communicated and accessed, distributed, and stored in a digital environment ( Mercader \& Gairín,
2020), giving students control over the place, time, path, and, or pace ( Kashada et al., 2018). These learning technologies include web-based learning systems, active learning classrooms (ALC), social media in the education context, mobile technologies, video conferencing applications, YouTube, and email (Granić \& Marangunić, 2019). However, students may experience difficulties utilizing these technologies because they are challenging to navigate and primarily dependent on internet access. Also, too many tools and links might distract them from their primary tasks (Zanjani et al., 2017). Therefore, designing a userfriendly e-learning tool with specific features allowing the students to navigate and easily access the instructional materials freely can positively affect their use and acceptance. Since DLT adoption and utilization are not always successful in students learning outcomes (Kashada et al., 2018), this study utilized a teacher-designed e-learning tool (e.g., Google Forms-based Lesson Playlist) based on the features of DLT that affect users' acceptance. Table 1 shows the identified characteristics of DLT that affect the user satisfaction and approval of a DLT.

Teachers' efforts to utilize innovative e-learning tools enable online distance learning (ODL) during the COVID-19 pandemic. In this study, the Google Forms-based Lesson Playlist was created considering the features mentioned in Table 1. A lesson playlist is a set of activities in a lesson that includes online links to video lessons, online articles, and interactive game-based activities. It may also include online formative assessments, summative assessments, reading assignments from student textbooks, etc. (Bohol \& Prudente, 2020). The lesson playlists used by the respondents of this study have the same template as this example http://bit.ly/SampleGF-LP. To ensure familiarity with the e-learning tool (See Table 3), the teachers used Google forms as the canvas to embed their instructional materials. 
Table 1. DLT Features Affecting User's Satisfaction

\begin{tabular}{ll}
\hline Features of DLT & Source \\
\hline $\begin{array}{l}\text { availability and flexibility, communication, simplicity in } \\
\text { learning, portability, cost, and efficiency }\end{array}$ & Asiimwe and Grönlund (2015) \\
$\begin{array}{l}\text { design factors such as perceived usefulness, appropriate } \\
\text { course management tools, and interactivity of the system, } \\
\text { perceived ease of use }\end{array}$ & Zanjani et al. (2017) \\
$\begin{array}{l}\text { familiarity with the technology } \\
\begin{array}{l}\text { system quality, interaction quality, service quality, and } \\
\text { platform availability }\end{array}\end{array}$ & Kashada et al. (2018) \\
\end{tabular}

\section{Extended Technology Acceptance Model}

Various studies extended the original Technology Acceptance Model (TAM) of Davis (1989) by defining its external variables. These Extended TAMs, which explains the adoption of technology by teachers (Scherer et al., 2020), is a valid model to test different learning technologies (Granić \& Marangunić, 2019) and to grasp the attitude of students and teachers towards the use of educational technology (Siyam, 2019). Table
2 shows the external variables employed in the studies utilizing Extended TAMs to examine the use of digital learning technologies.

In this study, system quality, perceived self-efficacy, and facilitating conditions were adopted as the external variables of the Extended Technology Acceptance Model because the features of the Google Forms-based Lesson Playlist (GF-LP) were directly based on them.

Table 2. External Variables of Extended TAM in Studies Assessing DLT Adoption

\begin{tabular}{|c|c|}
\hline Source & External Variables \\
\hline Tarhini et al. (2014) & social norm, self-efficacy \\
\hline Tarhini et al. (2016) & $\begin{array}{l}\text { social norm, quality of work-life, self-efficacy, facilitating } \\
\text { conditions }\end{array}$ \\
\hline Salloum (2018) & $\begin{array}{l}\text { self-efficacy, subjective norm, perceived enjoyment, system } \\
\text { quality, information quality, content quality, accessibility, } \\
\text { perceived playfulness }\end{array}$ \\
\hline Binyamin et al. (2019) & $\begin{array}{l}\text { content quality, learning support, visual design, system } \\
\text { navigation, ease of access, system interactivity, instructional } \\
\text { evaluation, and system learnability }\end{array}$ \\
\hline Fearnley \& Amora (2020) & system quality, perceived self-efficacy, and facilitating conditions \\
\hline
\end{tabular}




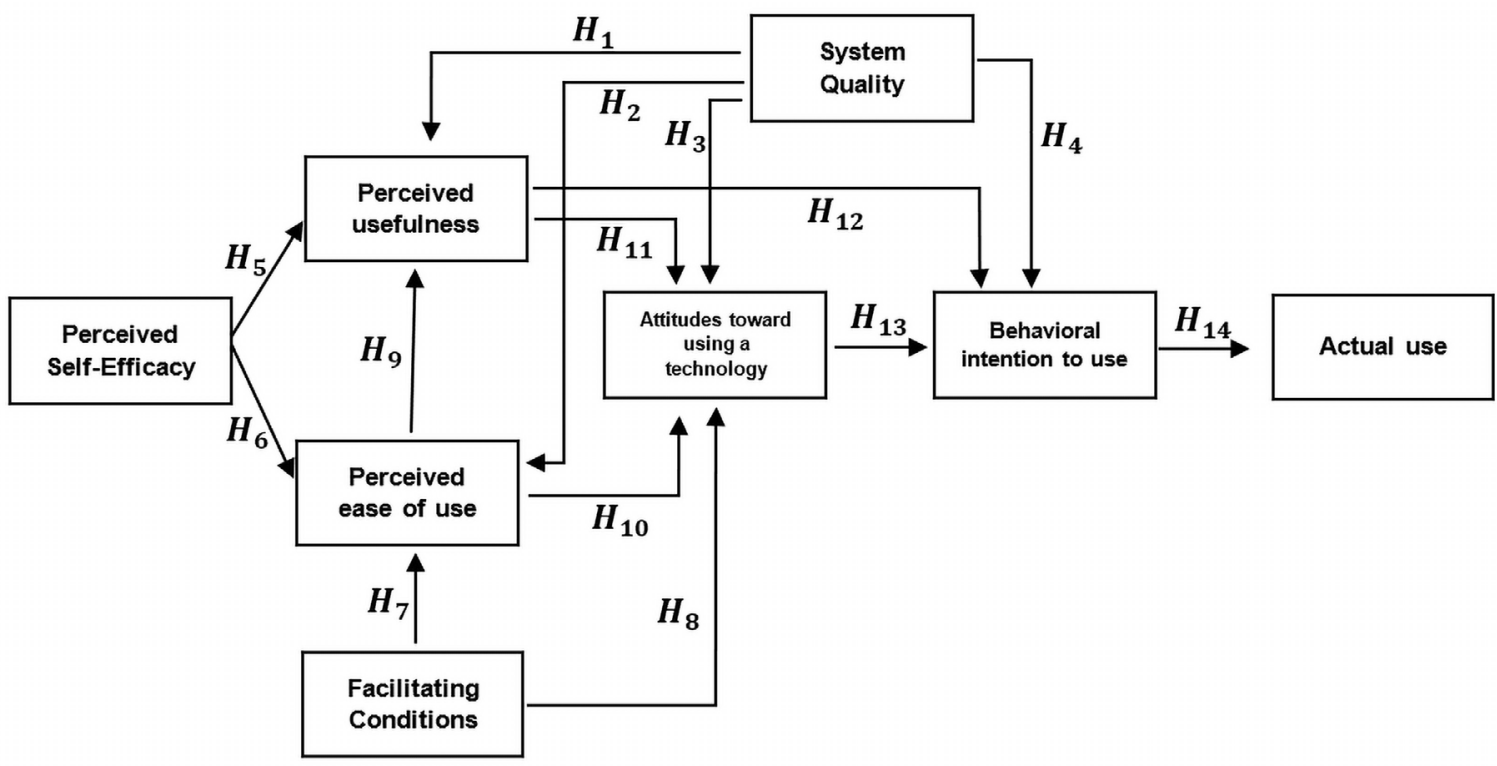

Figure 1. Extended Technology Acceptance Model for students' acceptance of Google Forms - based Lesson Playlist adopted from Fathema et al. (2015)

\section{Conceptual Framework and Research Hypotheses}

To examine the use of Google Forms-based Lesson Playlist in an Online Distance Learning using the Extended Technology Acceptance Model, the variables in Figure 1 are defined operationally. System quality (SQ) is defined as the satisfaction of the students in using the Google Forms-based Lesson Playlist (GF-LP) in terms of features, content quality, system interactivity and navigation, and adaptability in the ODL context (Binyamin et al., 2019; Fearnley \& Amora, 2020). The studies of Fathema et al. (2015); Fearnley and Amora (2020) showed that system quality influences perceived usefulness and ease of use. Nevertheless, they do not support each other on the effect of SQ on attitude towards the use of technology. This study hypothesized that if the students are satisfied with the quality of the e-learning tool, they have positive attitudes towards its use. These attitudes may affect their intention to use this tool in the future.
Facilitating conditions (FC) refer to an individual's perceived enablers that aid technology adoption (Teo et al., 2018). When a user expects assistance and specializes instruction when using technology, it positively affects his/ her perceived ease of use and attitude towards using the technology (Fathema et al., 2015; Teo et al., 2018). But this study hypothesized that facilitating conditions do not affect the students' attitude towards using the teacher-designed e-learning tool. Teachers designed the e-learning tool to provide students all the necessary assistance by developing a tool flexible enough to supplement the uncertainties or barriers of the online distance learning environment. This study measured facilitating conditions based on the teacher's assistance to students using the Google Forms-based Lesson Playlist.

According to Fathema et al. (2015), perceived self-efficacy (PSE) is the users' belief in performing the tasks necessary to achieve the required 
outcomes. This study shows that teachers' PSE is the predictor of perceived usefulness and perceived ease. When the students can carry out the tasks, they will find the GF-LP valuable and easy to use despite the barriers of digital technology adoption in an online distance learning environment.

Perceived usefulness (PU) was defined by Davis (1989) as "the degree to which a person believes that using a particular system would enhance his or her job performance" (p. 320). Similarly, he defined the perceived ease of use (PEOU) as "the degree to which a person believes that using a particular technology would be free from effort." The systematic literature review conducted by Granić and Marangunić (2019) showed that perceived usefulness and perceived ease of use are the predictors of technology adoption in an educational context emphasizing perceived usefulness as the stronger predictor. In particular, the PU and PEOU directly affect the attitude and the behavioral intention to use the technology (Fathema et al., 2015; Teo \& Huang, 2019; Fearnley \& Amora, 2020). Their study found that perceived ease of use predicts perceived usefulness. Hence, in this study, it is hypothesized that if the students perceive the GF-LP as easy to use, they will consider this useful. Consequently, this will influence their attitude and intention to use this e-learning tool in future ODL activities despite the barriers of DLTs adoption.

Hence, this study posited the following hypotheses to confirm the results of the previous studies on a self-made e-learning tool called Google Forms-based Lesson Playlist (GF-LP).

H1: System Quality (SQ) directly influences the perceived usefulness (PU) of GF-LP.

H2: System Quality (SQ) directly influences the perceived ease of use (PEOU) of GF-LP.
H3: System Quality (SQ) directly influences the attitude (ATT) towards using the GF-LP.

H4: System Quality (SQ) directly influences the behavioral intention (BI) to use the GF-LP.

H5: Perceived Self-Efficacy (PSE) directly influences the perceived usefulness (PU) of GF-LP.

H6: Perceived Self-Efficacy (PSE) directly influences the perceived ease of use (PEOU) of GF-LP.

H7: Facilitating Conditions (FC) directly influence the perceived ease of use (PEOU) of GF-LP.

H8: Facilitating Conditions (FC) do not affect the attitude (ATT) towards using the GF-LP.

H9: Perceived ease of use (PEOU) directly influences the perceived usefulness (PU) of GF-LP.

H10: Perceived ease of use (PEOU) directly influences the attitude (ATT) towards GF-LP use.

H11: Perceived usefulness (PU) directly influences the attitude (ATT) towards GFLP use.

H12: Perceived usefulness (PU) directly influences the behavioral intention $(\mathrm{BI})$ to use the GF-LP.

H13: Attitude (ATT) towards the use of GF-LP directly influences the behavioral intention (BI) to use GF-LP.

$\mathrm{H} 14$ : Behavioral intention (BI) directly influences the actual use (AU) of the GFLP.

\subsection{Methodology}

The current study examined the students' utilization of Google Forms-based Lesson Playlist as an e-learning tool in a home-based online 
distance learning environment. This study adopted the conceptual and operational definitions of home-based online distance learning from the next-generation digital learning environment (NGDLE) of Brown et al. (2015). It describes the home-based online distance learning environment as a virtual learning space composed of an instructor, students, learning materials, and tools to support self-paced learning.

\section{Participants of the Study}

Five-hundred seventy (570) responses were obtained from Grades 11 and 12 students whose subjects utilized Google Forms-based Lesson Playlist as presented in Table 3. The respondents' ages range from 16 to 19 years old. The consent letters were uploaded to the parents' portal and also distributed to the students. The current study used the inverse square root and gamma exponential post-hoc power analysis methods to calculate the minimum sample size. With the smallest significant path coefficient $=0.133$, $\alpha=0.05$, and $1-\beta=0.942$, the minimum sample size was between 568 and 585 . Thus, the sample size of this study is sufficient for $94.2 \%$ statistical power.

Table 4 presents the demographic profile of the respondents. There were 253 (44.39\%) male and 317 (55.61\%) female students whose majority $(27.72 \%)$ used a combination of tablet, smartphone, and laptop/desktop computer during the home-based online distance learning. The majority of the respondents (91.76\%) are moderate to extremely familiar with Google Forms. Approximately 12 percent of the students reported that they were not satisfied with their internet access; a majority (39.47\%) were slightly satisfied; 35.61 percent were moderately satisfied; 8.60 percent were very satisfied; and 3.86 percent were extremely satisfied.

Table 3. Number of Responses per subject that uses Google Forms - based Lesson Playlist

\begin{tabular}{lll}
\hline Level & Subjects & Responses \\
\hline G11 & Science Enrichment 3 & 10 \\
& Fundamentals of ABM 1 & 11 \\
& Personal Development & 12 \\
& Understanding Culture, & 30 \\
& Society \& Politics & \\
& English For Academic and & 32 \\
& Professional Purposes & \\
& Applied Economics & 39 \\
& Pre-Calculus & 45 \\
\hline G12 & Basic Calculus & 52 \\
& Enrichment 2 & \\
& Physical Science & 88 \\
& Science Enrichment 3 & 95 \\
& Mathematics Enrichment 3 & 156 \\
\hline \multicolumn{2}{c}{ Total Responses (N) } & $\mathbf{5 7 0}$ \\
\hline
\end{tabular}


Table 4. Demographic Profile of the Respondents $(N=570)$

\begin{tabular}{|c|c|c|}
\hline Variables & frequency & percentage \\
\hline \multicolumn{3}{|l|}{ Sex } \\
\hline Male & 253 & 44.39 \\
\hline Female & 317 & 55.61 \\
\hline \multicolumn{3}{|l|}{ Mobile Learning Device Used } \\
\hline Tablet & 25 & 4.39 \\
\hline Smartphones & 1 & 0.18 \\
\hline Tablet/smartphones & 11 & 1.93 \\
\hline Laptop/desktop computer & 156 & 27.37 \\
\hline Tablet, laptop/desktop computer & 66 & 11.58 \\
\hline Smartphone, laptop/desktop computer & 153 & 26.84 \\
\hline tablet, smartphones, laptop/desktop computer & 158 & 27.72 \\
\hline \multicolumn{3}{|l|}{ Internet access satisfaction } \\
\hline Extremely satisfied & 71 & 3.86 \\
\hline Very satisfied & 225 & 8.60 \\
\hline Moderately satisfied & 203 & 35.61 \\
\hline Slightly satisfied & 49 & 39.47 \\
\hline Not at all satisfied & 22 & 12.46 \\
\hline \multicolumn{3}{|l|}{ Familiarity with Google Forms } \\
\hline Extremely familiar & 378 & 66.32 \\
\hline Moderately familiar & 145 & 25.44 \\
\hline Somewhat familiar & 42 & 7.37 \\
\hline Slightly familiar & 3 & 0.53 \\
\hline Not familiar at all & 2 & 0.35 \\
\hline Total & 570 & 100.00 \\
\hline
\end{tabular}

\section{Research Instrument}

An online survey through Google Forms was utilized for the data collection. The questionnaire has three parts: (1) Introduction - this includes the objectives of the study, informed consent to the participants, and the e-Form Confidentiality; (2) Demographic Profile - this section comprises participant's gender, type of MLD used, level of familiarity in using Google Forms, and internet access satisfaction.; and (3) Survey Questionnaire
- adapted from Fathema et al. (2015) with 28 items all rated using a four-point Likert scale: $1=$ strongly disagree, $2=$ disagree, $3=$ agree, and $4=$ strongly agree.

\section{Data Gathering Procedure}

The participants of the study answered the online survey questionnaire with the help of their respective subject teachers. The study was conducted during the third term (January 25, 2021 
- April 8, 2021) of the academic year when the school adopted the home-based online distance learning to address the limitation of meeting face-to-face brought by the COVID-19 pandemic. The institution approved the conduct of the study following the ethical guidelines in data collection.

\section{Data Analysis}

The students' acceptance of the Google Forms-based Lesson Playlist was analyzed by examining the underlying relationships between the Extended TAM variables of Fathema et al. (2015) using the partial least squares-structural equation modeling (PLS-SEM). According to Granić and Marangunić (2019), PLS-SEM is the most commonly used data analysis technique when TAM is involved and becomes the recommended multivariate statistical technique for examining e-learning related research (Lin, H. et al., 2020).

\subsection{Results and Discussion}

The analysis using PLS-SEM was adopted from Janadari et al. (2018) and performed using WarpPLS Version 7.0. First, the validity and reliability tests were conducted, followed by the hypothesis tests relevant to the research framework.

\section{Reliability and Validity}

Fornell and Larcker (1981) and Kock (2020) suggested that the construct reliability is acceptable if the composite reliability (CR) is greater than $\geq 0.70$ and the Cronbach's alpha (CA) is greater than $\geq 0.70$.

Table 5 presents the construct and convergent validity as the construct reliability (CR) and Cronbach's alpha (CA) are at least 0.70 and the factor loadings and AVE are more than 0.50 .

The discriminant validity was determined using the Fornell-Larker criterion with the condition that is if the $\sqrt{\text { AVE }}$ (diagonal values) is greater than any of the off-diagonal values, then that particular construct is more highly correlated with its items than with the other constructs in the model (Fornell \& Larcker, 1981). Since any $\sqrt{\text { AVE }}$ shown in Table 6 is greater than any of the off-diagonal values, then discriminant validity was achieved by all the constructs.

Table 5. Factor loadings, AVE, and Reliability of Constructs

\begin{tabular}{lccccc}
\hline \multicolumn{1}{c}{ Constructs } & No. of items & Factor loadings & AVE & CA & CR \\
\hline System Quality & 4 & $.897-.925$ & .911 & .932 & .951 \\
Perceived Self-Efficacy & 3 & $.844-.902$ & .881 & .856 & .912 \\
Facilitating Conditions & 3 & $.896-.910$ & .904 & .889 & .931 \\
Perceived Usefulness & 4 & $.909-.934$ & .921 & .940 & .957 \\
Perceived Ease of Use & 4 & $.775-.910$ & .872 & .894 & .927 \\
Attitude Towards Using GF-LP & 4 & $.898-.941$ & .929 & .947 & .962 \\
Behavioral Intention & 3 & $931-.950$ & .942 & .936 & .959 \\
Actual Use & 3 & $.915-.961$ & .942 & .936 & .959 \\
\hline
\end{tabular}

All factor loadings are significant at $0.001(p<0.001)$. AVE = average variance extracted; $C A=$ Cronbach's alpha; $C R=$ composite reliability 
Table 6. Correlation Coefficients and VAVE values of the constructs

\begin{tabular}{lllllllll}
\hline & SQ & PSE & FC & PU & PEOU & ATT & BI & AU \\
\hline SQ & $(.954)$ & & & & & & & \\
PSE & .761 & $(.939)$ & & & & & & \\
FC & .681 & .724 & $(.951)$ & & & & & \\
PU & .747 & .738 & .720 & $(.960)$ & & & & \\
PEOU & .727 & .739 & .707 & .770 & $(.934)$ & & & \\
ATT & .730 & .736 & .665 & .802 & .738 & $(.964)$ & & \\
BI & .741 & .704 & .648 & .771 & .727 & .856 & $(.971)$ & \\
AU & .742 & .711 & .662 & .775 & .737 & .793 & .796 & $(.971)$ \\
\hline
\end{tabular}

Note: The square roots of average variances extracted (AVE) of constructs are shown on diagonal. The offdiagonal values are the correlation between constructs. All $p<.001$.

Kock (2020) recommends discussing the quality indices shown in Table 7 to determine if the model shown in the conceptual framework has a better fit. Table 7 shows the six quality indices, namely average path coefficient (APC), average R-squared (ARS), average adjusted R-squared (AARS), average block VIF, average full collinearity VIF (AFVIF), and Tenenhaus goodness of fit (GoF). For the structural model to be fit, APC, ARS, and AARS must be significant. That is, their corresponding $\mathrm{p}$-value must be less than 0.05 (Kock, 2020). Since the coefficients of APC $=0.319$, ARS $=0.693$, and AARS $=0.691$ have $p$-values less than 0.05 , then the structural model fits with the original data.

Regarding AVIF and AFVIF, their coefficients must have values less than 5 or ideally less than 3.3 (Kock, 2020). Table 6 shows that both coefficients of AVIF and AFVIF are within acceptable ranges. GoF is a measure of the explanatory power of the structural model (Tenenhaus et al., 2005), where it is small if GoF $\geq 0.1$, medium if GoF $\geq 0.25$, and large if GoF $\geq 0.36$ (Kock, 2020). Since GoF = 0.760 , then the explanatory power of the model is large. Overall, the structural model shown in the research framework is highly acceptable.

Table 7. Model Fit and Quality Indices

\begin{tabular}{ll}
\hline Index & Coefficient \\
\hline average path coefficient (APC) & $0.319, \mathrm{p}<0.001$ \\
average R-squared (ARS) & $0.693, \mathrm{p}<0.001$ \\
average adjusted R-squared (AARS) & $0.691, \mathrm{p}<0.001$ \\
average block VIF (AVIF) & 2.805 (acceptable if 5, ideally 3.3) \\
average full collinearity VIF (AFVIF) & 3.782 (acceptable if 5, ideally 3.3) \\
Tenenhaus goodness of fit (GoF) & 0.760 (large if $>0.36)$ \\
\hline
\end{tabular}


Table 8. Extended TAM Parameter estimates for GF-LP

\begin{tabular}{|c|c|c|c|c|c|}
\hline Hypotheses & $\beta$ & p-value & SE & $f^{2}$ & Results \\
\hline $\mathrm{H} 1: \mathrm{SQ} \rightarrow \mathrm{PU}$ & .289 & $<.001$ & .041 & .217 & Supported \\
\hline $\mathrm{H} 2: \mathrm{SQ} \rightarrow \mathrm{PEOU}$ & .306 & $<.001$ & .040 & .223 & Supported \\
\hline H3: SQ $\rightarrow$ ATT & .192 & $<.001$ & .041 & .140 & Supported \\
\hline $\mathrm{H} 4: \mathrm{SQ} \rightarrow \mathrm{BI}$ & .214 & $<.001$ & .041 & .160 & Supported \\
\hline H5: PSE $\rightarrow$ PU & .232 & $<.001$ & .041 & .171 & Supported \\
\hline H6: PSE $\rightarrow$ PEOU & .308 & $<.001$ & .040 & .228 & Supported \\
\hline $\mathrm{H7:FC} \rightarrow$ PEOU & .276 & $<.001$ & .041 & .195 & Supported \\
\hline $\mathrm{H} 8: \mathrm{FC} \rightarrow \mathrm{ATT}$ & .056 & .089 & .042 & .037 & Not Supported \\
\hline H9: PEOU $\rightarrow$ PU & .394 & $<.001$ & .040 & .305 & Supported \\
\hline H10: PEOU $\rightarrow$ ATT & .240 & $<.001$ & .041 & .181 & Supported \\
\hline $\mathrm{H} 11: \mathrm{PU} \rightarrow \mathrm{ATT}$ & .435 & $<.001$ & .040 & .349 & Supported \\
\hline $\mathrm{H} 12: \mathrm{PU} \rightarrow \mathrm{BI}$ & .133 & $<.001$ & .041 & .102 & Supported \\
\hline H13: ATT $\rightarrow$ BI & .595 & $<.001$ & .039 & .510 & Supported \\
\hline $\mathrm{H} 14: \mathrm{BI} \rightarrow \mathrm{AU}$ & .803 & $<.001$ & .038 & .645 & Supported \\
\hline
\end{tabular}

Note: $f^{2}$ is Cohen's effect size: $.02=$ small, $.15=$ moderate, $.35=$ large; $\beta=$ path coefficient,

\section{Test of Research Hypotheses}

Table 8 shows that the system quality (SQ) has a positive effect on perceived usefulness (PU), perceived ease of use (PEOU), attitude (ATT) towards the use of the Google Forms-based Lesson Playlist (GF-LP), and their behavioral intention to use this e-learning tool. This result implies that a high SQ will result in high PU, PEOU, and ATT towards using the GF-LP. In particular, SQ has a significant moderate effect on the PEOU $\left(f^{2}=\right.$ $0.223)$ and $\mathrm{PU}\left(f^{2}=0.217\right)$, and a small effect on ATT $\left(f^{2}=0.140\right)$, and $\mathrm{BI}\left(f^{2}=0.160\right)$. This result supports the findings of Fathema et al. (2015), Salloum, et al. (2019), and Fearnley and Amora (2020). SQ proved to be a powerful predictor of students' PEOU of the GF-LP, which implies that designing the e-learning tool considering students' realities during a pandemic helps them utilize the technology with less mental effort. Consequently, they become aware of its usefulness in learning the lessons despite DLT adoption barriers. Furthermore,
PEOU and PU mediate the influence of SQ on ATT, which emphasizes that the desirable features and flexibility of the e-learning tool to adjust to the learning environment assure the positive attitudes towards the use of the digital learning technology during the pandemic. This result confirms Granić and Marangunić (2019) findings that PEOU and PU influence the users' attitudes towards using DLT irrespective of its types, features, and navigation tools. This study also extends that PEOU and PU are significant predictors of the ATT in a different learning environment, which is, in this study, a home-based online distance learning environment.

Table 8 also shows that perceived self-efficacy (PSE) positively affects the PU $(\beta=0.232)$ and PEOU $(\beta=0.308)$. This result means that students familiarity with digital technology positively and highly influences the ease of use and usefulness of that digital technology. This study reaffirms that students' PSE influences PU and PEOU, which means that the students showed confidence in 
using the features and functions of the GF-LP to carry out the required tasks in a home-based online distance learning environment. Similarly, they felt confident in controlling the time and pacing of the lessons with the e-learning tool. This result agrees with the findings of Fathema et al. (2015), Nikou and Economides (2019), and Fearnley and Amora (2020) that PEOU mediates the effect of PSE on PU across different DLTs, users, and learning environment.

Facilitating conditions (FC) significantly affect PEOU ( $\beta=0.276)$ but the positive effect on ATT is not significant, $f^{2}=0.037, \mathrm{p}>0.05$. This relationship implies that the students' perceived ease of the use of the GF-LP is directly affected by the teacher's support, but this does not influence their attitudes towards using the GF-LP. Consistent with the hypothesis in this study, FC does not affect ATT, which contradicts Fathema et al. (2015) and Teo et al. (2018). This difference may be due to a different learning environment and digital learning technology. This study confirms that the GF-LP is a useful e-learning tool during home-based online distance learning since the students' attitudes towards using the playlists were not affected by the facilitating conditions. The possible reason could be that the teachers designed the e-learning tool so that the students can work independently on their activities. With this result, the use of Google Formsbased Lesson Playlist is an effective e-learning tool during home-based online distance learning.

PEOU positively and significantly affects ATT and PU, and consequently, PU positively affects both ATT and BI. These findings suggest that when there is a high value on PEOU, the students perceived high usefulness in the GF-LP, which leads to a high impact on their attitudes and behavioral intentions to utilize it. This study reports that PEOU and PU are strong predictors of accepting the GF-LP, consistent with the TAM-related studies (Granić \& Marangunić, 2019). In particular, PU significantly mediates the effect of PEOU on the students' attitudes towards the use of GF-LP in a home-based ODL environment. When the students feel that the e-learning tool is easy to use, useful in acquiring the course's competencies, and relevant in increasing their productivity despite the pandemic, they have positive attitudes and intentions to use that e-learning tool. Perceived usefulness is the most vital determinant of the student's attitude towards the use of GF-LP, consistent with the findings of Teeroovengadum et al. (2017), Granić and Marangunić (2019), and Fearnley and Amora (2020). This result showed that PU is consistently the robust determinant of technology acceptance in different countries and users, various digital learning technologies, and diverse learning environments. The strong positive effect of the students' attitudes to their behavioral intentions towards GF-LP use consequently proves the effective utilization (AU) of the GF-LP. In conclusion, the GF-LP adoption in a home-based online distance learning environment during the COVID-19 pandemic was successful.

ATT positively influences $\mathrm{Bl}$, and in turn, $\mathrm{BI}$ positively and significantly affects the actual use (AU) of GF-LP. The high effect of ATT on BI $\left(f^{2}=\right.$ 0.510 ) led to a stronger behavioral intention to use the GF-LP and consequently positively affects the technology's actual use $\left(f^{2}=0.645\right)$.

\subsection{Conclusion and Recommendation}

This study utilized the Extended Technology Acceptance Model by Fathema et al. (2015) to examine the use of Google Forms-based Lesson Playlist (GF-LP) as an e-learning tool in a homebased online distance learning. Perceived selfefficacy (PSE) and system quality (SQ) have the most substantial effect on users' perceived ease of use (PEOU) while PEOU strongly influences digital learning technology's perceived usefulness (PU). Facilitating conditions (FC) have a small 
impact on PEOU but no significant effect on the students' attitudes towards using the Google Forms-based Lesson Playlist. This result implies that when educators carefully design a digital learning technology (DLT) addressing its adoption barriers, the students can independently use that technology without difficulty while they increase their productivity in accomplishing the tasks with less assistance from the teacher. This study also found out that PU highly influences the students' attitudes towards using GF-LP compared to SQ and PEOU. The positive and high effect of ATT on the students' behavioral intentions ( $\mathrm{BI}$ ) to use GF$L P$ and the similar effect of $B I$ on the actual use of GF-LP imply that the use of GF-LP during online distance learning was favorable to the students.

This study contains limitations that open opportunities for future studies. The constructs used in examining students' acceptance of technology were adopted from Fathema et al. (2015). Hence, this study highly recommends future researchers explore other Extended TAM constructs in users with different cultures Hanif et al., 2018, different ages and education levels (Putra, 2019), and various learning environments. The current research also suggests conducting a longitudinal survey (Salloum et al., 2019) and a mixed-method approach (Fearnley \& Amora, 2020) to provide a deep understanding of the power of Extended TAM constructs.

\section{Conflict of Interest}

None.

\section{Ethical Clearance}

The institution approved it.

\section{References}

Adnan, M., \& Anwar, K. (2020). Online learning amid the COVID-19 pandemic: Students' perspectives. Journal of Pedagogical Sociology and Psychology, 2(1), 45-51. https://doi. org/10.33902/JPSP.

Almaiah, M. A., Alamri, M. M., \& Al-rahmi, W. (2019). Applying the UTAUT model to explain the students ' acceptance of mobile learning system in higher education. IEEE Access, 7, 174673-174686. https://doi.org/10.1109/ ACCESS.2019.2957206

Ancho, I. (2020). Graduate education during COVID-19 pandemic: Inputs to policy formulation in the new normal. Recoletos Multidisciplinary Research Journal, 8(2), 87-105. https://doi.org/10.32871/rmrj2008.02.07

Asiimwe, E. N., \& Grönlund, Å. (2015). MLCMS actual use, perceived use, and experiences of use. International Journal of Education and Development Using Information and Communication Technology, 11(1), 101-121. https://files.eric.ed.gov/fulltext/EJ1061487. pdf

Binyamin, S. S., Rutter, M. J., \& Smith, S. (2019). Extending the Technology Acceptance Model to understand students' use of learning management systems in Saudi higher education. International Journal of Emerging Technologies in Learning, 14(3), 4-21. https:// doi.org/10.3991/ijet.v14i03.9732

Bohol, D. O., \& Prudente, M. S. (2020, January 1012). Using lesson playlist through schoologybased Flipping The Classroom (FTC) approach in enhancing STEM students' performance in General Biology 1 [Conference session]. The 11th International Conference on E-Education, E-Business, E-Management, and E-Learning, Osaka, Japan. https://doi. org/10.1145/3377571.3377588 
Brown, M., Dehoney, J., \& Millichap, N. (2015). The next generation digital learning environment: $A$ report on research [ELI Paper]. https://library. educause.edu/resources/2015/4/the-nextgeneration-digital-learning-environment-areport-on-research

Chen, T., Peng, L., Jing, B., Wu, C., Yang, J., \& Cong, G. (2020). The impact of the COVID-19 pandemic on user experience with online education platforms in China. Sustainability, 12(18), 7329. https://doi.org/10.3390/SU12187329

Davis, F. D. (1989). Perceived usefulness, perceived ease of use, and user acceptance of information technology. MIS Quarterly, 13(3), 319-340. https://doi.org/10.2307/249008

Fathema, N., Shannon, D., \& Ross, M. (2015). Expanding the Technology Acceptance Model (TAM) to examine faculty use of Learning Management Systems (LMSs) in higher education institutions. MERLOT Journal of Online Learning and Teaching, 11(2), 210-232. https://www.researchgate. net/publication/281842180_Expanding_ The_Technology_Acceptance_Model_TAM_ to_Examine_Faculty_Use_of_Learning_ Management_Systems_LMSs_In_Higher_ Education_Institutions

Fearnley, M.R., \& Amora, J. T. (2020). Learning management system adoption in higher education using the extended technology acceptance model. IAFOR Journal of Education, 8(2), 89-106. https://doi.org/10.22492/ ije.8.2.05

Fei, V. L., \& Hung, D. (2016). Teachers as learning designers: What technology has to do with learning. A view from Singapore. Educational
Technology, 56(4), 26-29. https://www. researchgate.net/publication/306080401_ Teachers_as_Learning_Designers_What_ Technology_has_to_do_with_Learning_A_ View_from_Singapore\#: :text $=1 \mathrm{t} \% 20$ proposes $\% 20$ that $\% 20$ as $\% 20$ a, the $\% 20$ mastery\%20of\%20subject\%20knowledge.

Fornell, C., \& Larcker, D. F. (1981). Evaluating structural equation models with unobservable variables and measurement error. Journal of Marketing Research, 18(1), 39. https://doi. org/10.1177/002224378101800104

Granić, A., \& Marangunić, N. (2019). Technology acceptance model in educational context: A systematic literature review. British Journal of Educational Technology, 50(5), 2572-2593. https://doi.org/10.1111/bjet.12864

Hanif, A., Jamal, F. Q., \& Imran, M. (2018). Extending the Technology Acceptance Model for use of e-learning systems by digital learners. IEEE Access, 6, 73395-73404. https://doi. org/10.1109/ACCESS.2018.2881384

Janadari, M. P. N., Ramalu, S. S., \& Wei, C. C. (2018). Measurement of organizational citizenship behaviour; reliability and validity in Sri Lankan context. Kelaniya Journal of Human Resource Management, 13(1), 1-9. http://doi. org/10.4038/kjhrm.v13i1.45

Kashada, A., Li, H., \& Koshadah, O. (2018). Analysis approach to identify factors influence digital learning technology adoption and utilization in developing countries. International Journal of Emerging Technologies in Learning, 13(2), 48-59. https://doi.org/10.3991/ijet. v13i02.7399 
Kock, N. (2020). WarpPLS 7.0 user manual : Version 7.0. https://www.scriptwarp.com/warppls/ UserManual_v_7_0.pdf

König, J., Jäger-Biela, D. J., \& Glutsch, N. (2020). Adapting to online teaching during COVID-19 school closure: Teacher education and teacher competence effects among early career teachers in Germany. European Journal of Teacher Education, 43(4), 608-622. https:// doi.org/10.1080/02619768.2020.1809650

Lin, H. M., Lee, M. H., Liang, J. C., Chang, H. Y., Huang, P., \& Tsai, C. C. (2020). A review of using partial least square structural equation modeling in e-learning research. British Journal of Educational Technology, 51(4), 1354-1372. https://doi.org/10.1111/bjet.12890

Mercader, C., \& Gairín, J. (2020). University teachers' perception of barriers to the use of digital technologies: The importance of the academic discipline. International Journal of Educational Technology in Higher Education, 17(4). https://doi.org/10.1186/s41239-0200182-x

Mothibi, G. (2015). A meta-analysis of the relationship between e-learning and students ' academic achievement in higher education. Journal of Educational and Practice, 6(9), 6-10. https://www.iiste.org/Journals/index.php/ JEP/article/view/21025

Nikou, S. A., \& Economides, A. A. (2019). Factors that influence behavioral intention to use mobile-based assessment: A STEM teachers' perspective. British Journal of Educational Technology, 50(2), 587-600. https://doi. org/10.1111/bjet.12609
Ozerbas, M. A., \& Erdogan, B. H. (2016). The effect of the digital classroom on academic success and online technologies self-efficacy. Educational Technology and Society, 19(4), 203-212. https://eric.ed.gov/?id=EJ1115665 \#: :text=This\%20study\%20aimed\%20to\%20 observe,efficacy $\% 20$ of $\% 207$ th\%20grade $\% 20$ students.\&text=However\%2C\%20it $\% 20$ has $\% 20$ been $\% 20$ shown,'\%20online $\% 20$ technologies\%20self\%2Defficacy.

Panda, S., \& Mishra, S. (2007). E-Learning in a Mega Open University: Faculty attitude, barriers, and motivators. Educational Media International, 44(4), 323-338. https://doi. org/10.1080/09523980701680854

Putra, I.D.G.R.D.(2019). The evolution ofTechnology Acceptance Model (Tam) and recent progress on technology acceptance research in Elt: State of the art article. Yavana Bhasha : Journal of English Language Education, 1(2), 25-37. https://doi.org/10.25078/yb.v1i2.724

Rajab, M. H., Gazal, A. M., \& Alkattan, K. (2020). Challenges to online medical education during the COVID-19 pandemic. Cureus, 12(7), e8966. https://doi.org/10.7759/cureus.8966

Salloum, S. A. (2018). Investigating students acceptance of E-learning system in higher educational environments in the UAE: Applying the extended Technology Acceptance Model (TAM) [Master's thesis, The British University in Dubai]. The British in Dubai Digital Repository. https://bspace.buid.ac.ae/handle/1234/1150

Salloum, S. A., Qasim Mohammad Alhamad, A., Al-Emran, M., Abdel Monem, A., \& Shaalan, K. (2019). Exploring students' acceptance of e-learning through the development of 
a comprehensive technology acceptance model. IEEE Access, 7, 128445-128462. https:// doi.org/10.1109/ACCESS.2019.2939467

Scherer, R., Siddiq, F., \& Tondeur, J. (2020). All the same or different? Revisiting measures of teachers' technology acceptance. Computers \& Education, 143, 103656. https://doi. org/10.1016/j.compedu.2019.103656

Siyam, N. (2019). Factors impacting special education teachers' acceptance and actual use of technology. Education and Information Technologies, 24(3), 2035-2057. https://doi. org/10.1007/s10639-018-09859-y

Tarhini, A., Elyas, T., Akour, M. A., \& Al-Salti, Z. (2016). Technology, demographic characteristics and e-learning acceptance: A conceptual model based on extended technology acceptance model. Higher Education Studies, 6(3), 72-89. https://doi.org/10.5539/hes.v6n3p72

Tarhini, A., Hone, K., \& Liu, X. (2014). Measuring the moderating effect of gender and age on e-learning acceptance in England: A structural equation modeling approach for an extended technology acceptance model. Journal of Educational Computing Research, 51(2), 163-184. https://doi.org/10.2190/ EC.51.2.b

Teeroovengadum, V., Heeraman, N., \& Jugurnath, B. (2017). Examining the antecedents of ICT adoption in education using an Extended Technology Acceptance Model (TAM). International Journal of Education and Development Using Information and Communication Technology, 13(3), 4-23. https://files.eric.ed.gov/fulltext/EJ1166522. pdf
Tenenhaus, M., Vinzi, V. E., Chatelin, Y. M., \& Lauro, C. (2005). PLS path modeling. Computational Statistics \& Data Analysis, 48(1), 159-205. https://doi.org/10.1016/j.csda.2004.03.005

Teo, T., \& Huang, F. (2019). Investigating the influence of individually espoused cultural values on teachers' intentions to use educational technologies in Chinese universities. Interactive Learning Environments, 27(5-6), 813-829. https://doi.org/10.1080/10494820. 2018.1489856

Teo, T., Huang, F., \& Hoi, C. K. W. (2018). Explicating the influences that explain intention to use technology among English teachers in China. Interactive Learning Environments, 26(4), 460 475. https://doi.org/10.1080/10494820.2017. 1341940

Toquero, C. M. (2020). Challenges and opportunities for higher education amid the COVID-19 pandemic: The Philippine context. Pedagogical Research, 5(4). https://doi. org/10.29333/pr/7947

Zanjani, N., Edwards, S. L., Nykvist, S., \& Geva, S. (2017). The important elements of LMS design that affect user engagement with e-learning tools within LMSs in the higher education sector. Australasian Journal of Educational Technology, 33(1), 19-31. https:// doi.org/10.14742/ajet.2938 